\title{
Motor skills of children with autism spectrum disorder
}

\section{Habilidades motoras de crianças com transtorno do espectro autista}

\author{
Gabriele Radünz Kruger \\ (DD https://orcid.org/ 0000-0002-7092-4968 \\ Jennifer Rodrigues Silveira ${ }^{1}$ \\ (D) https://orcid.org/0000-0002-9143-6824 \\ Alexandre Carriconde Marques \\ (D) https://orcid.org/0000-0002-1866-4169
}

Abstract - The objective of this study is to describe variables of life habits associated with motor skills of children with autism spectrum disorder aged 8-10 years living in the city of Pelotas / RS. A questionnaire about lifestyle was applied and the Test of Gross Motor Development-2 (TGMD-2) was applied to assess motor skills. Independent T-test, ANOVA and Wilcoxon test were used to compare means. The study consisted of 49 individuals (42 males). The results indicate that the higher the level of ASD, the better the motor skills. Children making use of medications have greater deficits in motor skills. Higher scores on motor skills are associated with greater participation in physical education classes. Motor skills are strongly associated with independence in activities of the daily living, food, personal hygiene, dressing and bathing. The importance of the creation of PA programs aiming at improving the motor skills of this population was highlighted.

Key words: Autism Disorder; Lifestyle; Motor skills; Physical activity.

Resumo - O objetivo deste estudo é descrever as variáveis de hábitos de vida associadas as habilidades motoras de crianças com transtorno do espectro autista de oito a 10 anos residentes na cidade de Pelotas/ $R S$. Foi respondido um questionário sobre o estilo de vida e aplicado o Test of Gross Motor Development-2 (TGMD-2) para avaliação das habilidades motoras. Foi utilizado o teste T independente, ANOVA e teste de Wilcoxon para comparação de médias. Fizeram parte do estudo 49 individuos (42 do sexo masculino). Os resultados indicam que quando maior o grau de TEA, melhor são as habilidades motoras. As crianças que tomam medicamento apresentam maiores déficits nas habilidade motoras. Maiores escores nas habilidades motoras, estão associados a maior participação nas aulas de educação física. As habilidades motoras estão fortemente associadas a independência nas atividades de vida diária, alimentar-se, higiene pessoal, arrumar-se e banhar-se. Pode-se perceber a importância da criação de programas de AF visando a melhora nas habilidades motoras dessa população.

Palavras-chave: Atividade física; Destreza Motora; Estilo de vida; Transtorno Autístico.
1 Federal University of Pelotas. Pelotas, RS. Brazil

Received: December 02, 2018 Accepted: July 22, 2019

How to cite this article Kruger GR, Silveira JR, Marques AC. Motor skills of children with autism spectrum disorder. Rev Bras Cineantropom Desempenho Hum 2019, 21:e60515. D0l: http://dx.doi. org/10.1590/1980-0037.2019v21e60515

Copyright: This work is licensed under a Creative Commons Attribution 4.0 International License. 


\section{INTRODUCTION}

People with Autism Spectrum Disorder (ASD) have impaired social and communication skills, restricted and stereotyped behaviors, and studies have also reported problems with motor deficits ${ }^{1}$. Regarding basic motor skills, people with ASD present impaired postural control' ${ }^{2}$, gait deficits ${ }^{3}$, impairments in broad motor coordination ${ }^{4}$, and deficit in fine motor skills ${ }^{1}$. As a result, it is known that impaired motor skills prevent participation in group physical activity programs ${ }^{5}$. Green et al. ${ }^{6}$, in a sample of 111 children with ASD aged 9-12 years, reported that 79\% had impairment and 10\% had borderline deficits in motor skills.

It was also observed that the development of these skills are fundamental, as these characteristics have been reported as barriers to regular PA practice ${ }^{7,8}$.

Children with good level of motor skills develop activities of the daily living with greater resourcefulness and independence. In addition, satisfactory motor condition contributes to the successful participation in exercise programs with regard to socialization in the practice environment ${ }^{9,10}$.

Thus, the aim of this study was to describe variables of life habits associated with the motor skills of children with autism spectrum disorder aged 8-10 years living in the city of Pelotas / RS.

\section{METHOD}

This research is a cross-sectional study.

\section{Sample}

The study population consisted of male and female children with ASD aged 8-10 years, living in the city of Pelotas, state of Rio Grande do Sul. The sample was intentionally selected, allowing the participation of the greater number of children.

\section{Instruments}

A lifestyle questionnaire ${ }^{9}$ was applied, which was responded by parents or guardians. This questionnaire was adapted based on the characteristics of the population studied and was divided into two parts: identification and family data (general children's data, educational information and sociodemographic characteristics) and lifestyle characteristics (questions related to PA, activities of the daily living and usual activities during free time).

The Test of Gross Motor Development-2 (TGMD-2) ${ }^{11}$ was applied, which assesses broad motor development in locomotion and object control skills. TGMD is used to evaluate broad motor performance containing 12 items - six are locomotion skills such as running, jogging, jumping on one foot, jumping with both feet, side running and slide; and six are object control skills such as bouncing, receiving, kicking, throwing over the shoulder, and rolling a ball ${ }^{12}$. TGMD allows carrying out a separate 
evaluation of each item (locomotion and object control). The test protocol suggests the use of a camcorder so that the motor performance can be later analyzed. Each sub-item has several performance criteria according to the video analysis: the child is given one (1) point if he/she can meet the criteria correctly and no point if he/she does not. Subsequently, the points obtained in each sub-item named in the test as raw scores are summed up. According to raw data, the lowest score is zero and the highest is 26 in the evaluation of locomotor skills and 19 in the evaluation of object control skills. In the present study, a researcher received training to examine the test skills in conjunction with another researcher.

All tests were analyzed by two evaluators; in case of divergence, the test was sent to a third person who again performed evaluation and decision making.

\section{Procedures}

The research was submitted and approved by the Research Ethics Committee of the School of Physical Education - Federal University of Pelotas. All participants had the Free and Informed Consent Form signed by parents / guardians, agreeing to participate, maintaining the ethical precepts of research with human beings.

\section{Statistical analysis}

To analyze data collected, descriptive statistics was used through mean and standard deviation. Normality and homogeneity were verified by ShapiroWilk and Levene tests, respectively, only for the sample characterization data. For comparison between means of parametric variables, the independent $t$ test or ANOVA was used and for nonparametric ones, the Wilcoxon test was used. The significance level adopted in this study was 5\%. The SPSS 20.0 statistical package was used for all tests. The significance level adopted was $\mathrm{p} \leq 0.05$.

For data analysis, parametric statistics resources were used, where central tendency measures (means and standard deviation) and frequencies were observed for the description of results. Data were analyzed using SPSS 20.0 software.

\section{RESULTS}

Forty-nine $(n=49)$ individuals were located and all agreed to participate in the study. Table 1 shows a description of the main characteristics of children.

Three children had brothers with disabilities, one with ASD, one with schizophrenia and one with intellectual deficit. Fourteen $(n=14)$ children reported some health problem, five described bronchitis, four rhinitis, four sinusitis and one epilepsy. Of the 37 children making use of some type of medication, 20 take more than one medication, most of them antidepressant combined with anxiolytic. The most cited drug was risperidone, being consumed by 25 children. 
Of the 17 children who perform PA in their free time, only one meets the World Health Organization (WHO) recommendation of 300 minutes per week. The free time physical activities performed by children were swimming, walking, cycling, psychomotor activities, dance, futsal and volleyball.

Table 2 describes association between the total motor skills score and lifestyle variables. Level of ASD, medication use, participation in PE classes, activities of the daily living such as eating, personal hygiene and dressing were significantly associated with motor skills score.

Table 1. Characterization of children with ASD aged 8-10 years in the city of Pelotas/RS $(n=49)$

\begin{tabular}{|c|c|c|}
\hline Variable & $N=49$ & $\%$ \\
\hline \multicolumn{3}{|l|}{ Sex } \\
\hline Boys & 42 & 85.7 \\
\hline Girls & 7 & 14.3 \\
\hline \multicolumn{3}{|l|}{ Age (years) } \\
\hline 08 years & 20 & 40.8 \\
\hline 09 years & 12 & 24.5 \\
\hline 10 years & 17 & 34.7 \\
\hline \multicolumn{3}{|c|}{ Age (years) diagnosed with autism } \\
\hline 01 to 03 & 21 & 42.8 \\
\hline 04 to 06 & 17 & 34.7 \\
\hline 07 to 10 & 11 & 22.4 \\
\hline \multicolumn{3}{|c|}{ Presence of any disease } \\
\hline Yes & 14 & 28.6 \\
\hline No & 35 & 71.4 \\
\hline \multicolumn{3}{|c|}{ Make use of medication } \\
\hline Yes & 37 & 75.5 \\
\hline No & 12 & 24.5 \\
\hline \multicolumn{3}{|c|}{ Level of ASD reported by physician } \\
\hline Light & 28 & 57.1 \\
\hline Moderate & 15 & 30.6 \\
\hline Severe & 6 & 12.2 \\
\hline \multicolumn{3}{|l|}{ Level of ASD by CARS } \\
\hline Light to moderate & 36 & 73.5 \\
\hline Severe & 13 & 26.5 \\
\hline \multicolumn{3}{|l|}{ School frequency } \\
\hline Yes & 48 & 98.0 \\
\hline No & 1 & 2.0 \\
\hline \multicolumn{3}{|c|}{ Attend physical education classes } \\
\hline Yes & 38 & 77.6 \\
\hline No & 11 & 22.4 \\
\hline \multicolumn{3}{|c|}{ Physical activity in free time } \\
\hline Yes & 17 & 34.7 \\
\hline No & 32 & 65.3 \\
\hline
\end{tabular}


Table 2. Association between motor skill test score and lifestyle variables of children with ASD from Pelotas / RS

\begin{tabular}{|c|c|c|c|}
\hline & Mean & SD & $p$ \\
\hline Age & & & 0.07 \\
\hline 8 years & 27.6 & 25.7 & \\
\hline 9 years & 41.0 & 23.7 & \\
\hline 10 years & 44.8 & 20.1 & \\
\hline Sex & & & 0.223 \\
\hline Male & 38.6 & 23.4 & \\
\hline Female & 26.4 & 28.8 & \\
\hline Health problems & & & 0.563 \\
\hline Yes & 40.1 & 21.5 & \\
\hline No & 35.6 & 25.6 & \\
\hline CARS & & & 0.001 \\
\hline Light to moderate & 45.0 & 18.7 & \\
\hline Severe & 14.3 & 24.1 & \\
\hline Level of ASD reported by parents & & & 0.001 \\
\hline Light & 51.4 & 14.9 & \\
\hline Moderate & 19.1 & 20.0 & \\
\hline Severe & 13.5 & 23.4 & \\
\hline Make use of medications & & & 0.003 \\
\hline Yes & 31.1 & 22.8 & \\
\hline No & 54.4 & 20.7 & \\
\hline Attend physical education class & & & 0.002 \\
\hline Yes & 42.4 & 21.6 & \\
\hline No & 17.7 & 23.9 & \\
\hline Practice PA in free time & & & 0.232 \\
\hline Yes & 47.6 & 21.6 & \\
\hline No & 33.8 & 25.4 & \\
\hline Activities of the Daily Living & & & 0.084 \\
\hline \multicolumn{4}{|l|}{ Dressing } \\
\hline Yes & 39.9 & 22.2 & \\
\hline With difficulty & 38.1 & 23.6 & \\
\hline No & 20.6 & 22.5 & \\
\hline Feeding & & & 0.02 \\
\hline Yes & 40.3 & 23.0 & \\
\hline With difficulty & 9.2 & 18.5 & \\
\hline No & 19.0 & 26.9 & \\
\hline Personal hygiene & & & 0.01 \\
\hline Yes & 44.0 & 23.2 & \\
\hline With difficulty & 40.9 & 23.4 & \\
\hline No & 20.8 & 20.8 & \\
\hline Getting ready & & & $<0.001$ \\
\hline Yes & 51.5 & 17.7 & \\
\hline With difficulty & 42.8 & 20.9 & \\
\hline No & 17.4 & 21.0 & \\
\hline Bathing & & & $<0.001$ \\
\hline Yes & 52.2 & 12.5 & \\
\hline With difficulty & 37.5 & 21.4 & \\
\hline No & 16.4 & 18.7 & \\
\hline
\end{tabular}




\section{DISCUSSION}

Regarding motor skills, the study demonstrates important associations. The results indicate that the lower the level of ASD, the better the motor skills. Children who make use of medications have greater motor skill deficits. Higher motor skills scores are associated with higher participation in physical education classes. Moreover, motor skills are strongly associated with independence in activities of the daily living - eating, personal hygiene, dressing and bathing.

Significant associations were found in relation to the level of severe ASD and lower motor skills test score, which is found both in relation to parents' report and in CARS assessment. It was observed in this study that children with higher level of ASD also have lower motor skills. This fact may be directly related to the cognitive and behavioral characteristics found in the most severe levels of ASD, which according to Staples and $\operatorname{Reid}^{13}$, contribute to atypical development, presenting deficits and delays in the motor skills of children with ASD. These authors report that children with ASD have motor skills equivalent to children half their age.

Likewise, association between motor skills and medication use was observed, and no studies correlating this variable with motor skills were found in literature; however, a link can be made with level of ASD, as children with mild levels, most often receive only non-medication treatment such as PA, as observed by Memari et al. ${ }^{14}$, who found that regular PA practice increases drug sensitivity.

ASD is characterized by deficits in social interaction, language and communication, and restricted and stereotyped behaviors. It is known that physical education has among its objectives to assist in the physical, mental and affective development of students. In addition, with PA practice, children with ASD improve simple commands that provide an improvement in motor skills and communication ${ }^{15}$. Studies in this area are still scarce; however, the importance of the participation of these children in PE classes is highlighted, which may reflect on the positive modification of their lifestyle.

No significant association was found in relation to PA practice and motor skills; however, it is clear that the mean TGMD-2 score of active children was higher than the average score of non-active children. It is understood that for PA to contribute to the improvement of motor skills, it should be stimulated in children with ASD from early childhood; however, we did not observe this fact today. Jones et al. ${ }^{16}$, through a literature review, found that children with $\mathrm{ASD}$ have low levels of $\mathrm{PA}$, in some cases presenting average of $34 \mathrm{~min} /$ day in moderate / vigorous $\mathrm{PA}^{17,18}$, not meeting PA recommendations suggested by WHO and that the sedentary behavior of these children is high, reaching up to 11 hours per day in sedentary activities. Similarly, the author showed that as the children's school age or educational level increases, PA level decreases.

In the present study, significant association between variables of activities of the daily living - eating, personal hygiene, dressing and bathing 
- and having better motor skills score was found. It is observed that motor skills are directly related to activities of the daily living, thus providing greater autonomy and independence in these activities. However, no studies presenting this comparison in children with ASD were found in literature.

As limitations, the present study uses a convenience sample. Although the sample is for convenience, we sought to reach the largest number of children with ASD in the main reference centers of the city. The strengths are highlighted because this population has received little attention from the scientific community, and studies in literature are scarce, in addition to the pioneering in studying the motor skills and daily life characteristics of children with ASD.

\section{CONCLUSION}

According to results, it could be concluded that motor skills have an important relationship with lifestyle variables, since there is significant association with level of ASD, i.e., the more severe the ASD, the greater the deficit in motor skills and in addition, children who make use of medication also present deficits. Higher motor skills scores are associated with higher participation in physical education classes, and finally, motor skills are strongly associated with independence in activities of the daily living.

Considering the findings of this study, the importance of creating PA programs aiming at improving the motor skills of this population is highlighted. In addition, increased opportunities for PA practice and intervention research in this area may encourage greater adherence to $\mathrm{PA}$ practices, with positive reflexes in lifestyle and consequent improvement in quality of life.

\section{COMPLIANCE WITH ETHICAL STANDARDS}

\section{Funding}

This research did not receive any specific grant from funding agencies in the public, commercial, or not-profit sectors. This study was funded by the authors.

\section{Ethical approval}

Ethical approval was obtained from the local Human Research Ethics Committee -Federal University of Pelotas and the protocol (no. 70687417.3.0000.5313) was written in accordance with standards set by the Declaration of Helsinki.

\section{Conflict of interest statement}

The authors have no conflict of interests to declare.

\section{Author Contributions}

Conceived and designed the experiments: GK and AM. Performed the experiments: GK and AM. Analyzed the data: GK and AM. Contributed with reagents/materials/analysis tools: GK and AM. Wrote the paper: GK, JR and AM. 


\section{REFERENCES}

1. McPhillips M., Finlay J, Bejerot S, Hanley M. Motor Deficits in Children With Autism Spectrum Disorder: A Cross-Syndrome Study. Autism Res 2014;7:664-676

2. Freitag CM, Kleser C, Schneider M, Gontard A. Quantitative Assessment of Neuromotor Function in Adolescents with High Functioning Autism and Asperger Syndrome. J Autism Dev Disord 2007;37:948-959.

3. Rinehart NJ, Bellgrove MA, Tonge BJ, Brereton AV, Howells-Rankin D, Bradshaw JL. An Examination of Movement Kinematics in Young People with High-functioning Autism and Asperger's Disorder: Further Evidence for a Motor Planning Deficit. J Autism Dev Disord 2006;36(6): 757-767.

4. Kaur M, Srinivasan SM, Bhat AN. Comparing motor performance, praxis, coordination, and interpersonal synchrony between children with and without Autism Spectrum Disorder (ASD). Res Dev Disabil 2018;72:79-95.

5. Stins JF, Emck C. Balance Performance in Autism: A Brief Overview. Front Psychol 2018;9:901.

6. Green D, Charman T, Pickles A, Chandler S, Loucas T, Simonoff E, Baird G. Impairment in movement skills of children with autistic spectrum Disorders. Dev Med Child Neurol 2009;51(4):311-6.

7. Krüger GR. Atividade física e barreiras em crianças com autismo de Pelotas. [Dissertação de Mestrado- Programa de pós-graduação da Escola Superior de Educação Física] Pelotas(RS): Universidade Federal de Pelotas; 2015.

8. Must A, Phillips SM, Curtin C, Bandini LG. Barriers to physical activity in children with autism spectrum disorders: relationship to physical activity and screen time. J Phys Act Health 2015;12(4): 529-534.

9. Marques AC. O perfil do estilo de vida de pessoas com Síndrome de Down e normas para avaliação da aptidão física [Tese de Doutorado -Programa de pós-graduação da Escola Superior de Educação Física] Porto Alegre(RS): Universidade Federal do Rio Grande do Sul; 2008.

10. Sowa M, Meulenbroek R. Effects of physical exercise on Autism Spectrum Disorders: A meta-analysis. Res Autism Spectr Disord 2012; 6:46-57.

11. Ulrich D. The test of gross motor development. Austin: Prod-Ed; 2000.

12. Valentini N. Percepções de Competência e Desenvolvimento Motor de meninos e meninas: um estudo transversal. Movimento 2002;8(2):51-62.

13. Staples, KL. Reid, G. J. Fundamental movement skills and autism spectrum disorders. Autism Dev Disord 2010;40:209.

14. Memari AH, Ghaheri B, Ziaee V, Kordi R, Hafizi S, Moshayedi P. Physical activity in children and adolescents with autism assessed by triaxial accelerometry. Pediatr Obes 2013;8(2):150-8.

15. Lima HR, Viana FC. Importância da educação física para inserção escolar de crianças com transtorno do espectro do autismo (TEA). Rev Cie Multidiscip Núcleo Conhecim 2016;1(10):261-280.

16. Jones RA, Downing K, Rinehart NJ, Barnett LM, May T, McGillivray JA, et al. Physical activity, sedentary behavior and their correlates in children with Autism Spectrum Disorder: A systematic review. Plos One 2017;12(2):e0172482.

17. Ayvazoglu NR, Kozub FM, Butera G, Murray MJ. Determinants and challenges in physical activity participation in families with children with high functioning autism spectrum disorders from a family systems perspective. Res Dev Disabil 2015;47:93-105.

18. Orsmond GI, Kuo H-Y. The daily lives of adolescents with an autism spectrum disorder: Discretionary time use and activity partners. Autism 2011;15: 579-599. 